\title{
The relative importance of seed competition, resource competition and perturbations on community structure
}

\author{
K. Bohn ${ }^{1,2}$, J. G. Dyke ${ }^{1}$, R. Pavlick ${ }^{1,3}$, B. Reineking ${ }^{2}$, B. Reu ${ }^{1,4}$, and A. Kleidon ${ }^{1}$ \\ ${ }^{1}$ Max Planck Institut für Biogeochemie, P.O. Box 1001 64, 07701 Jena, Germany \\ ${ }^{2}$ Biogeographical Modelling, BayCEER, University of Bayreuth, Universitätsstrasse 30, 95440 Bayreuth, Germany \\ ${ }^{3}$ International Max Planck Research School on Earth System Modelling, Hamburg, Germany \\ ${ }^{4}$ Institute of Geography, University Bonn, Bonn, Germany
}

Received: 5 October 2010 - Published in Biogeosciences Discuss.: 9 November 2010

Revised: 18 March 2011 - Accepted: 28 April 2011 - Published: 11 May 2011

\begin{abstract}
While the regional climate is the primary selection pressure for whether a plant strategy can survive, however, competitive interactions strongly affect the relative abundances of plant strategies within communities. Here, we investigate the relative importance of competition and perturbations on the development of vegetation community structure. To do so, we develop DIVE (Dynamics and Interactions of VEgetation), a simple general model that links plant strategies to their competitive dynamics, using growth and reproduction characteristics that emerge from climatic constraints. The model calculates population dynamics based on establishment, mortality, invasion and exclusion in the presence of different strengths of perturbations, seed and resource competition. The highest levels of diversity were found in simulations without competition as long as mortality is not too high. However, reasonable successional dynamics were only achieved when resource competition is considered. Under high levels of competition, intermediate levels of perturbations were required to obtain coexistence. Since succession and coexistence are observed in plant communities, we conclude that the DIVE model with competition and intermediate levels of perturbation represents an adequate way to model population dynamics. Because of the simplicity and generality of DIVE, it could be used to understand vegetation structure and functioning at the global scale and the response of vegetation to global change.
\end{abstract}

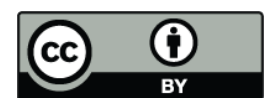

Correspondence to: K. Bohn (kbohn@bgc-jena.mpg.de)

\section{Introduction}

Plant community dynamics are largely determined by the interrelated effects of climate, competition and perturbations. Climate represents the primary selection pressure for vegetation at the global scale (Woodward, 1987), and determines the general performance of plants, such as biomass and seed production. At local scales, general plant performance affects competitive interactions for resources and space and thereby determines plant species composition. For instance, a large tree can exclude small grasses by over-shading and may thus dominate the community. Perturbations, such as fire, disease or abiotic stress, influence community composition by increasing available space (Sousa, 1984). With higher levels of perturbations, available space increases, allowing fast growing small grasses with high seed production to rapidly establish and escape competitive exclusion by larger trees.

The interplay of competition and perturbations in shaping community structure is altered when environmental conditions change. Since plant species respond differentially to altered environmental conditions (e.g. Körner, 1998; Sandel et al., 2010), competition for space and resources is affected (Grime, 1977; Raizada et al., 2009). These changes in performance and therefore competition may alter succession and steady states (in the sense of equilibrium or climax vegetation, Clements, 1936), with consequences for plant composition (Hughes, 2000; Zavaleta et al., 2003; Parmesan and Yohe, 2003; Hoegh-Guldberg et al., 2008; Sandel et al., 2010) and ecosystem processes such as carbon and nutrient cycling (Shaver et al., 2000; Bunker et al., 2005; Fisher et al., 2010). For example, water stress may reduce tree shading and allow for an increase in coverage of smaller

Published by Copernicus Publications on behalf of the European Geosciences Union. 
grasses. Consequently, in order to predict how vegetation will respond to environmental change, both, the performance of individual species and their competitive interactions need to be adequately considered in vegetation models.

A range of models has been developed to simulate the dynamics of species composition and its response to environmental change. These can broadly be classified into three groups. First, several theoretical models exist to explain the coexistence of species in plant communities based on colonisation, competition and mortality (e.g. Tilman, 1994; Tilman and Kareiva, 1997). However, rates of colonisation and mortality are represented by aggregated parameters and are not related to underlying mechanisms. Consequently, there is no explicit link to plant ecophysiology. Second, gap models simulate competition between individual plants, e.g. for water and light, in a process-based fashion based on plant geometry (e.g. Bugmann, 2001). However, this group of models requires empirical parameterisation of plant geometry, e.g. how crown area depends on individual tree growth (e.g. Badeck et al., 2001). In addition, these models are computationally expensive to run, and are thus usually only applied on local or regional scales. Third, Dynamic Global Vegetation Models (DGVMs) calculate population dynamics but use only a few plant functional types (PFT) to simulate global biogeography and biogeochemical patterns (e.g. Box, 1981; Foley et al., 1996; Sitch et al., 2003; Woodward and Lomas, 2004). Coexistence of different PFTs in DGVMs is often empirically prescribed. For instance, grasses are always present with a minimum fractional coverage or only when the soil water content is above a certain threshold (e.g. Sitch et al., 2008; Haxeltine and Prentice, 1996). Some DGVMs need to predefine e.g. species specific invasion rates or dominances of PFTs to calculate population dynamics (Cox, 2001; Arora and Boer, 2006). However, due to climatic change as well as spatial and temporal climate variability, such parameters could vary. Therefore, such values should rather be emergent properties from plant growth or seed production. To overcome some of these limitations, some global approaches have integrated gap model ideas into DGVMs to get a more realistic and process-based vegetation composition (e.g. ED - Moorcroft et al., 2001; Fisher et al., 2010, SEIB-DGVM Sato et al., 2007, LPJ-GUESS - Hickler et al., 2004). These new models still require intensive empirical parameterisations and are very complex because they consider a large number of processes at a high level of detail.

In this study, we seek a less complex approach in which population dynamics is still process-based by relating individual plant population performance to the emergent community structure. We developed the model DIVE (Dynamics and Interactions of VEgetation) that simulates whole populations of plant strategies (PPS), rather than individuals. DIVE calculates population dynamics based on establishment, mortality, invasion and exclusion as distinct processes that are shaped by competition between seeds for available space, competition for resources and perturbations. The rates of es- tablishment, mortality, invasion and exclusion are linked to the modelled emergent performances of different plant strategies derived from an individual-based plant model (Kleidon and Mooney, 2000; Reu et al., 2011), that covers how individual plant strategies cope with their environment without considering interspecies competition. By doing so, we do not need to predefine the dominance or the colonization rates of the PFTs. Furthermore, we implement competition in a way, such that we can separately control not only the strength of seed competition (Arora and Boer, 2006), but also resource competition and perturbations.

We used the DIVE model and applied it to a hypothetical tropical environment. To understand the effect and role of different types of competition and perturbations on community structure and dynamics, we performed several sensitivity simulations in which we varied the strength of seed competition, resource competition and perturbations. We analysed the simulations in terms of their temporal dynamics and the resulting diversity in the climax state. Thereby we can relate different strength of competition and perturbation to the emergent successional dynamics and coexistence in the model. The results are discussed in terms of the plausibility of the dynamics, inherent limitations and potential application of the model in further studies.

\section{Model description}

\subsection{Overview}

The purpose of DIVE is to capture population dynamics from perturbations and competition between different plant population strategies (PPSs). DIVE calculates population dynamics as the consequence of different characteristics of PPSs in terms of their biomass, seed flux, growth and mortality rate. These characteristics are derived from the output of the Jena Diversity (JeDi) model (Kleidon and Mooney, 2000; Reu et al., 2011). This model filters many random plant strategies that grow independently from each other to yield those, that can cope with the climate from the fundamental assumption of unavoidable ecophysiological trade-offs. We used the following mean output from JeDi that describes mean population characteristics without considering the number of individuals in a population: biomass, seed flux, litter flux, respiration and productivity of a seedling (see Fig. 1 and Table 1). This constant set of output data was used as input for all DIVE simulations. The stocks and fluxes are calculated per unit occupied area $\left(\mathrm{gC} \mathrm{m}^{-2}\right.$ or $\mathrm{gC} \mathrm{m}^{-2} \mathrm{~d}^{-1}$, respectively).

DIVE calculates the change in occupied area in fractions of all PPSs in time within a homogenous area on a daily time step. Each PPS is initialised with an amount of seeds. PPSs increase in covered area by establishment (seeding bare area) or invading area covered by other PPSs. Decreases in area are due to exclusion and mortality (death). Competition of seeds to establish and competition for resources to invade are 


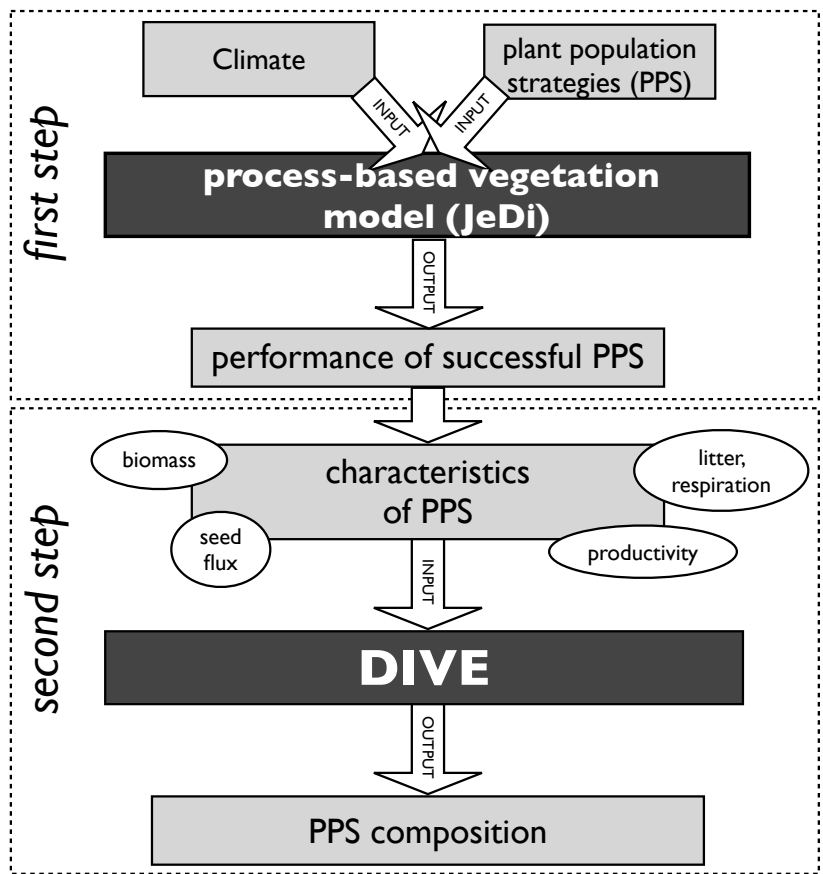

Fig. 1. Flow chart diagram of the model setup. First JeDi is run to produce the necessary input for DIVE (ellipses) to calculate population dynamics by competition.

controlled by two independent parameters. A third parameter controls perturbations that result in low or high mortality. Table 1 lists all model parameters and variables.

\subsection{Population dynamics}

The fractional area $A_{i}$ occupied by PPS $i$ changes due to four processes:

$\frac{d A_{i}}{d t}=S_{i}-M_{i}+I_{i}-E_{i}$

with establishment $S_{i}\left[\mathrm{~m}^{2} \mathrm{~m}^{-2} \mathrm{~d}^{-1}\right]$ on the fraction of bare area, mortality $M_{i}\left[\mathrm{~m}^{2} \mathrm{~m}^{-2} \mathrm{~d}^{-1}\right]$, which includes the effect of disturbances, invasion $I_{i}\left[\mathrm{~m}^{2} \mathrm{~m}^{-2} \mathrm{~d}^{-1}\right]$ into area occupied by other PPS and exclusion $E_{i}\left[\mathrm{~m}^{2} \mathrm{~m}^{-2} \mathrm{~d}^{-1}\right]$ by other PPS. Bare, i.e. non vegetated, fractional area $A_{\text {bare }}$ is given by subtracting the sum over fractional areas $A_{i}$ of all PPSs from the total of $100 \%$.

$A_{\text {bare }}=1-\sum_{i=1}^{n} A_{i}$

\subsection{Establishment and seed competition}

Establishment describes how much bare area can be covered by each PPS by germination of the seeds in one time step (see Fig. 2a-d). We assume that all seeds from all PPSs are well mixed and that establishment happens only on bare ground and not in shade below existing populations. Establishment
Table 1. Model variables and parameters used in DIVE.

\begin{tabular}{|c|c|c|}
\hline Symbol & Meaning & Unit/Value \\
\hline \multicolumn{3}{|c|}{ Output of JeDi, Input to DIVE: PPS performance } \\
\hline $\mathrm{BM}_{i}$ & $\begin{array}{l}\text { biomass of PPS } i \\
\text { per } \mathrm{m}^{2} \text { of occupied (occ.) area }\end{array}$ & $\mathrm{gC} \mathrm{m}^{-2}$ \\
\hline$f_{\text {seed }, i}$ & $\begin{array}{l}\text { seed flux of } i \\
\text { per } \mathrm{m}^{2} \text { of occ. area }\end{array}$ & $\mathrm{gC} \mathrm{m}^{-2} \mathrm{~d}^{-1}$ \\
\hline$f_{\mathrm{npp} i}^{0}$ & seedling net primary productivity & $\mathrm{gC} \mathrm{m}^{-2} \mathrm{~d}^{-1}$ \\
\hline$f_{\mathrm{lit}, i}$ & $\begin{array}{l}\text { of PPS } i \text { per } \mathrm{m}^{2} \text { of occ. area } \\
\text { litter flux of PPS } i \\
\text { per } \mathrm{m}^{2} \text { of occ. area }\end{array}$ & $\mathrm{gCm}^{-2} \mathrm{~d}^{-1}$ \\
\hline$f_{\text {res }, i}$ & $\begin{array}{l}\text { respiration of PPS } i \\
\text { per } \mathrm{m}^{2} \text { of occ. area }\end{array}$ & $\mathrm{gCm}^{-2} \mathrm{~d}^{-1}$ \\
\hline$n$ & number of PPS & \\
\hline \multicolumn{3}{|c|}{ PPS Characteristics derived form JeDi output } \\
\hline$d_{i}$ & dominance of $i$ & \\
\hline$\kappa_{\text {grow }, i}$ & growth rate & $d^{-1}$ \\
\hline$\kappa_{\mathrm{mort}, i}$ & mortality rate & $d^{-1}$ \\
\hline & germination fraction & frac. \\
\hline$\alpha_{i j}$ & competition coefficient & \\
\hline$x_{i j}$ & invasion rates & $d^{-1}$ \\
\hline \multicolumn{3}{|c|}{ State variables and area rates } \\
\hline$A_{i}$ & fractional coverage of PPS $i$ & $\mathrm{~m}^{2} \mathrm{~m}^{-2}$ \\
\hline$S_{i}$ & rate of establishment of PPS $i$ & $m^{2} m^{-2} d^{-1}$ \\
\hline$I_{i}$ & rate of invasion of PPS $i$ & $\mathrm{~m}^{2} \mathrm{~m}^{-2} \mathrm{~d}^{-1}$ \\
\hline$E_{i}$ & rate of exclusion of PPS $i$ & $\mathrm{~m}^{2} \mathrm{~m}^{-2} \mathrm{~d}^{-1}$ \\
\hline$M_{i}$ & rate of mortality of PPS $i$ & $m^{2} m^{-2} d^{-1}$ \\
\hline$A_{\text {bare }}$ & fractional non covered area & $\mathrm{m}^{2} \mathrm{~m}^{-2}$ \\
\hline \multicolumn{3}{|c|}{ Parameters } \\
\hline$c_{\mathrm{R} 1}$ & seed competition strength & {$[1, \infty] \mathrm{m}^{2} \mathrm{dgC}^{-1}$} \\
\hline$c_{\mathrm{R} 2}$ & resource competition strength & {$[1, \infty]$} \\
\hline$c_{\text {Mort }}$ & perturbation factor & {$\left[10^{-3}, 10^{2}\right]$} \\
\hline
\end{tabular}

depends on the germination fraction of a PPS $g_{i}$ [frac.], the bare area $A_{\text {bare }}$ and on the growth rate $\kappa_{\text {grow }, i}\left[\mathrm{~d}^{-1}\right]$. The germination fraction $g_{i}$ describes how much of the total area could be occupied by the actual seed flux per PPS. Since we do not consider different age classes, incorporating the growth rate $\kappa_{\text {grow }, i}$ allows us to model the effective area gain by the whole population rather than the area that seedlings would cover. The inverse of the growth rate describes the time that a seedling needs to reach adult size.

$S_{i}=g_{i} \cdot A_{\text {bare }} \cdot \kappa_{\text {grow }, i}$

From each PPS's seed flux $f_{\text {seed, } i}\left[\mathrm{gC} \mathrm{m}^{2} \mathrm{~d}^{-1}\right]$, we calculate the germination fraction $g_{i}$ as a saturating function of numbers of seeds, so for a certain threshold of seed number, 


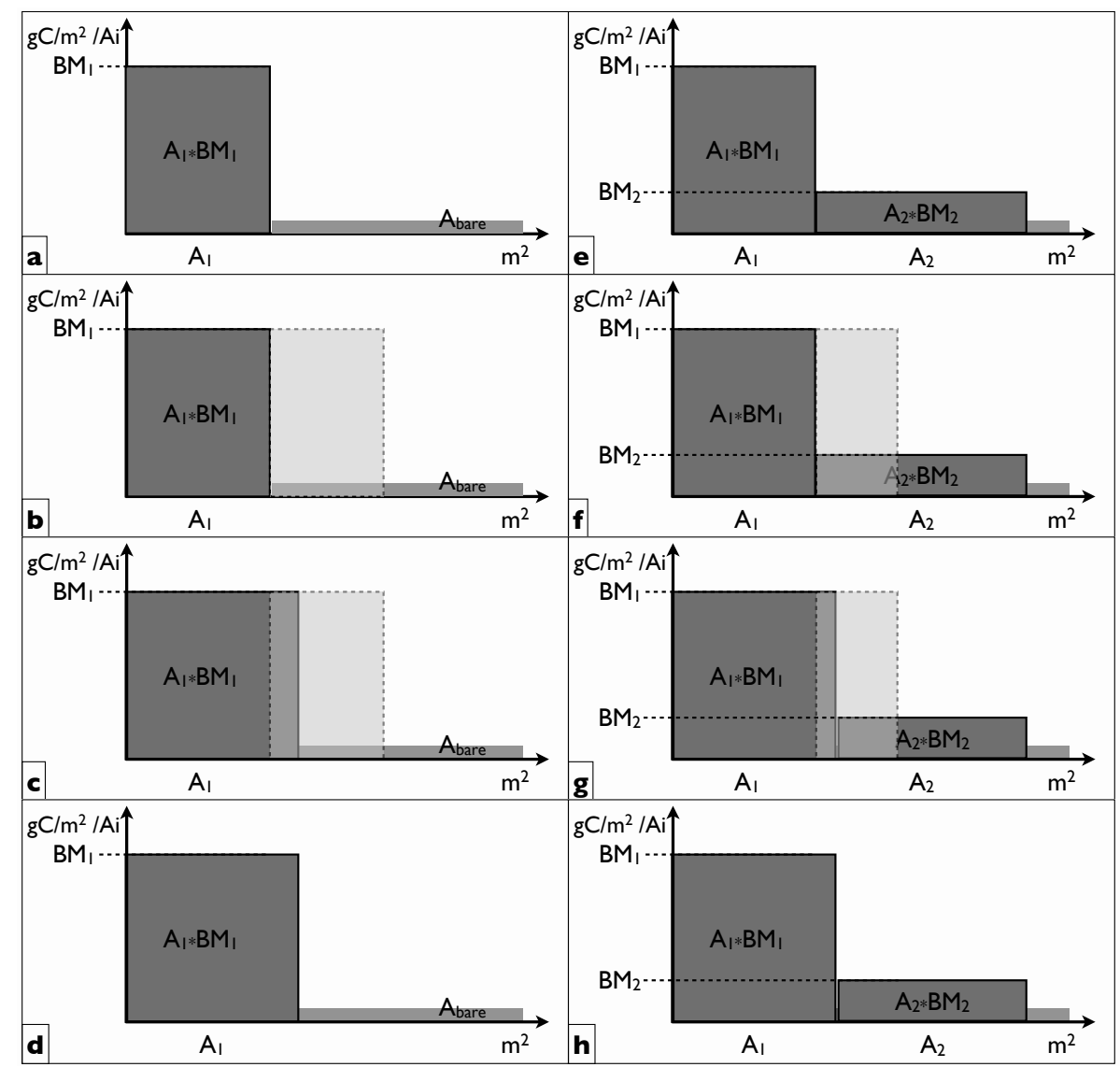

Fig. 2. Illustration of how area is gained via establishment (a-d) and invasion (e-h). PPS 1 occupies the area $A_{i}$ (a). The germination fraction would results in a large increase of area covered with seedlings (b). The actual gain in area by the average population is then determined by the growth rate (c and $\mathbf{d}$ ). If competition happens, the PPS with the higher biomass per occupied area (equivalent to dominance) can invade in the area of smaller PPS (e and $\mathbf{f}$ ). Again here the growth rate determines how much the average population would gain in area $(\mathbf{g}$ and $\mathbf{h})$.

producing more seeds does not lead to an increase in establishment:

$g_{i}=1-e^{-c_{\mathrm{R} 1} \cdot A_{i} \cdot f_{\mathrm{seed}, i}}$

A value of $g_{i}=1$ describes that a PPS has produced sufficient seeds to germinate on the whole area, a value of $g_{i}=0$ means that the seed flux is too low to start germination. If different PPSs have a different seed flux, then some will have the potential to gain more area than others. This will affect the establishment in future time steps via the available bare area. Therefore, seeds from different PPSs compete for bare area indirectly but do not have a direct effect on each other. To investigate what effects seed competition might have, we introduce a factor for seed competition strength, $c_{\mathrm{R} 1}$, that changes seed saturation (see Fig. 3). For $c_{\mathrm{R} 1}=1$, the seed flux is very important for establishment. If a PPS has a low seed flux, its germination rate and establishment will be low. For $c_{\mathrm{R} 1} \rightarrow \infty$, the seed flux becomes irrelevant for establishment (neutral seed competition). Then, every PPS will have the same germination fraction as long as one seed is produced.

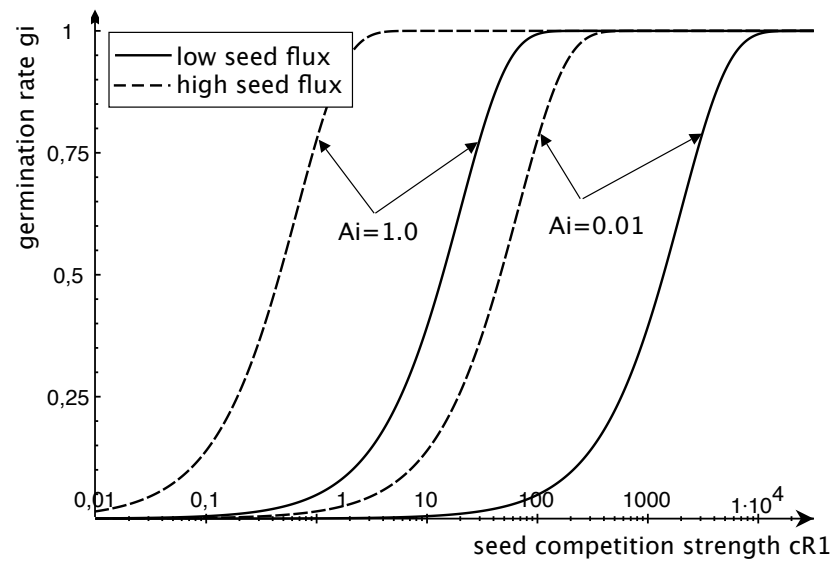

Fig. 3. Qualitative behavior of Eq. (4) with increasing seed competition for low and high seed flux PPS that occupy a low or high fraction of area. 


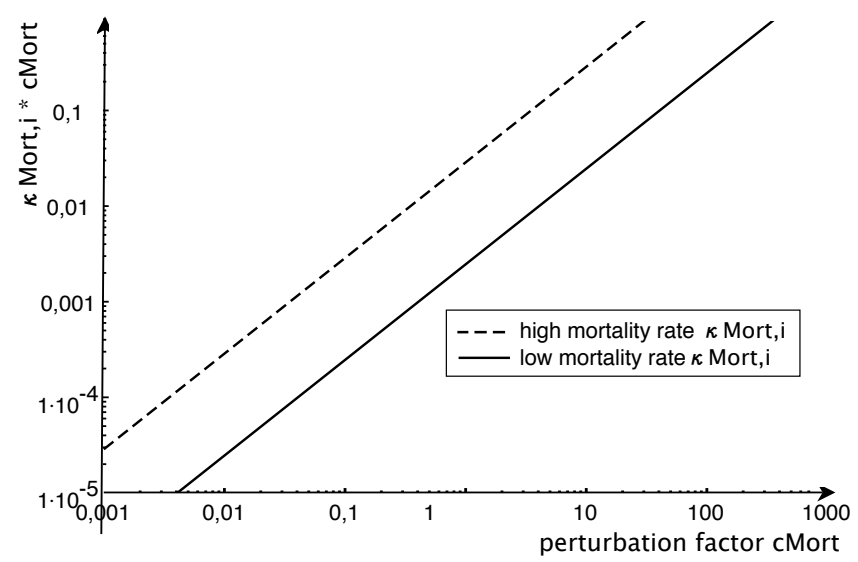

Fig. 4. The effect of perturbations on mortality (see Eq. 6) for a PPS with low and high mortality rate.

The growth rate $\kappa_{\text {grow, } i}$ is determined by the biomass per $\mathrm{m}^{2}$ of occupied area of $i \mathrm{BM}_{i}$ and the productivity of a seedling $f_{\mathrm{npp}, i}^{0}$ :

$\kappa_{\text {grow }, i}=\frac{f_{\mathrm{npp}, i}^{0}}{\mathrm{BM}_{i}}$

Note that the biomass is given per $\mathrm{m}^{2}$ of occupied area, and therefore the total biomass per $\mathrm{m}^{2}$ of the community is determined by $\sum_{k=1}^{n} \mathrm{BM}_{k} \cdot A_{k}$.

\subsection{Mortality and perturbations}

Mortality $M_{i}$ of PPS $i$, the death of individuals resulting in bare area, is modelled as the loss of coverage due to a PPS's mortality rate $\kappa_{\text {mort }, i}\left[\mathrm{~d}^{-1}\right]$ and on a factor that scales mortality: $c_{\text {Mort }}$.

$M_{i}=A_{i} \cdot \kappa_{\mathrm{mort}, i} \cdot c_{\mathrm{Mort}}$

We explore the effects of different intensities of perturbations via the use of $c_{\text {Mort }}$, a parameter that alters the mortality rate. Higher values for $c_{\text {Mort }}$ would correspond to more severe perturbations that would lead to an increase in mortality, e.g. due to grazing, herbivory, disease or harshness (e.g. Chesson and Huntly, 1997; Diaz et al., 2007). Low values of $c_{\text {Mort }}$ correspond to low intensity of perturbations and consequently lower mortality (see Fig. 4).

The PPS's mortality rate $\kappa_{\text {mort }, i}$ depends on the PPS characteristics. We calculate the mortality rate dependent on a PPS's biomass (e.g., McCoy and Gillooly, 2008) in relation to its carbon losses (respiration, $r_{i}$ and litter flux, $l_{i}$ $\left[\mathrm{gC} \mathrm{m}^{-2} \mathrm{~d}^{-1}\right]$.

$\kappa_{\mathrm{mort}, i}=\frac{f_{\mathrm{res}, i}+f_{\mathrm{lit}, i}}{\mathrm{BM}_{i}}$

In many cases, fast-growing plants live shorter, because they have higher metabolic rates, while slow-growing plants show the opposite pattern (e.g. Gillooly et al., 2001; Ricklefs, 1998; McCoy and Gillooly, 2008). With Eq. (7) we can distinguish the turnover time of slow versus fast-growing PPS. For example, a slow and a fast-growing PPS might have the same biomass, but will differ in their gross primary production (GPP). Since in steady state GPP equals the sum of litter fall and respiration, different mortality rates will result. We divide by biomass because mortality rates are predicted to be proportional to body size (Brown et al., 2004; Gillooly et al., 2001). We use biomass as a surrogate for body size, although they are decoupled by plant density, because our simplistic approach has no notion about individuals and the biomass of each PPS describes a whole population per $\mathrm{m}^{2}$ of occupied area. Therefore Eq. (7) allows abstraction from the carbon losses of a PPS into the loss of area. Note that mortality rates are calculated in an analogous manner to growth rates (see Eq. 5).

\subsection{Invasion and extinction resulting from resource competition}

Competition for resources is modelled implicitly by biomass dominance. We assume that size matters, in that larger plants will typically outcompete smaller ones. Therefore, in DIVE a large (high biomass) PPS can invade the area of smaller PPSs. Smaller PPSs become excluded due to e.g. being a poorer competitor for light, water or others resources (e.g. Siemann and Rogers, 2003). We calculate the competitive dominance and, respectively, the relative size $d_{i}$ of a PPS by normalising its biomass per $\mathrm{m}^{2}$ of occupied area $\mathrm{BM}_{i}$ with the sum of biomass of all $n$ PPSs:

$d_{i}=\frac{\mathrm{BM}_{i}}{\sum_{k=1}^{n} \mathrm{BM}_{k}}$

From the differences in dominance between two distinct PPSs $i$ and $j$ we obtain the competition coefficients $\alpha_{i j}$. To influence the intensity of resource competition we introduce a parameter $c_{\mathrm{R} 2}$ :

$\alpha_{i j}=\left\{\begin{aligned} 0 & \text { if } d_{i} \leq d_{j} \\ \left(d_{i}-d_{j}\right)^{c_{\mathrm{R} 2}} & \text { otherwise }\end{aligned}\right.$

With this formulation, PPS do not compete for resources when $c_{\mathrm{R} 2} \rightarrow \infty$, because $\left(d_{i}-d_{j}\right)^{\infty} \rightarrow 0$. The more dominant PPS $i$ outcompetes the smaller one $j$ proportional to its coverage. Therefore PPS $i$ invades the area $A_{j}$ of the less dominant PPS $j$ with the invasion rate $x_{i j}$, proportional to their competition coefficient $\alpha_{i j}$ and dependent on the growth rate, $\kappa_{\text {grow }, i}$ (analogous to establishment, Fig. $2 \mathrm{e}-\mathrm{h}$ ).

$x_{i j}=A_{i} \cdot \alpha_{i j} \cdot A_{j} \cdot \kappa_{\text {grow }, i}$

We assume that invasions into areas occupied by other PPSs do not depend on seed production. The sum of invasions of a PPS results in its total gain $I_{i}$, while the sum of all losses results in exclusion $E_{i}$.

$I_{i}=\sum_{j=1}^{n} x_{i j}$ 
Table 2. Values of PPS characteristics calculated in DIVE from the output of JeDi: dominance $d_{i}$, seed flux $f_{\text {seed, } i}$, growth rate $\kappa_{\text {grow }, i}$ and mortality rate $\kappa_{\text {mort }, i}$.

\begin{tabular}{ccccc}
\hline & $d_{i}$ & $f_{\text {seed }, i}$ & $\kappa_{\text {grow }, i}$ & $\kappa_{\text {mort }, i}$ \\
\hline PPS 1 & 0.497 & 0.059 & $0.035 \times 10^{-2}$ & $0.246 \times 10^{-2}$ \\
PPS 2 & 0.369 & 1.457 & $0.041 \times 10^{-2}$ & $0.311 \times 10^{-2}$ \\
PPS 3 & 0.112 & 1.273 & $0.127 \times 10^{-2}$ & $0.959 \times 10^{-2}$ \\
PPS 4 & 0.012 & 0.047 & $1.206 \times 10^{-2}$ & $1.768 \times 10^{-2}$ \\
PPS 5 & 0.010 & 0.688 & $0.515 \times 10^{-2}$ & $2.864 \times 10^{-2}$ \\
\hline
\end{tabular}

$E_{i}=\sum_{j=1}^{n} x_{j i}$

Note that the sum of invasions and exclusions is balanced, so that $\sum_{i=1}^{n} I_{i}+\sum_{i=1}^{n} E_{i}=0$.

\section{Simulation setup}

Because our focus is to understand the model behaviour of DIVE and the role of perturbations and competition for population dynamics, we use a simple setup (Fig. 1). In this setup we use a constant tropical climatic forcing to first derive a set of feasible plant population strategies and their growth characteristics. Then we select five strategies from this set and use them for the DIVE simulations.

\subsection{Climatic forcing}

We consider in the following a constant tropical-like climate. We prescribe a daily precipitation rate of $12 \mathrm{~mm} \mathrm{~d}^{-1}$, a mean incoming flux of solar radiation of $278 \mathrm{~W} \mathrm{~m}^{-2}$ and a near surface air temperature of $290 \mathrm{~K}$. We use the constant climate to explicitly avoid the effects of climatic variability on population dynamics.

\subsection{Selection of PPS}

We used the JeDi model (Kleidon and Mooney, 2000; Reu et al., 2011) to generate the performances of a whole range of PPSs. JeDi models diverse vegetation from ecophysiological assumptions based on trade-offs. JeDi uses climate data (see previous section) and a large set of vectors with randomly assigned traits, that describe characteristics such as allocation, phenology, light use efficiency and senescence. These traits correspond to ecophysiological properties. JeDi then models the growth, reproduction and death of these trait vectors, calculates land surface fluxes and $C$-fluxes. The JeDi model and has successfully reproduced global patterns of plant diversity, abundance distributions and biomes (Kleidon and Mooney, 2000; Kleidon et al., 2009; Reu et al., 2011).

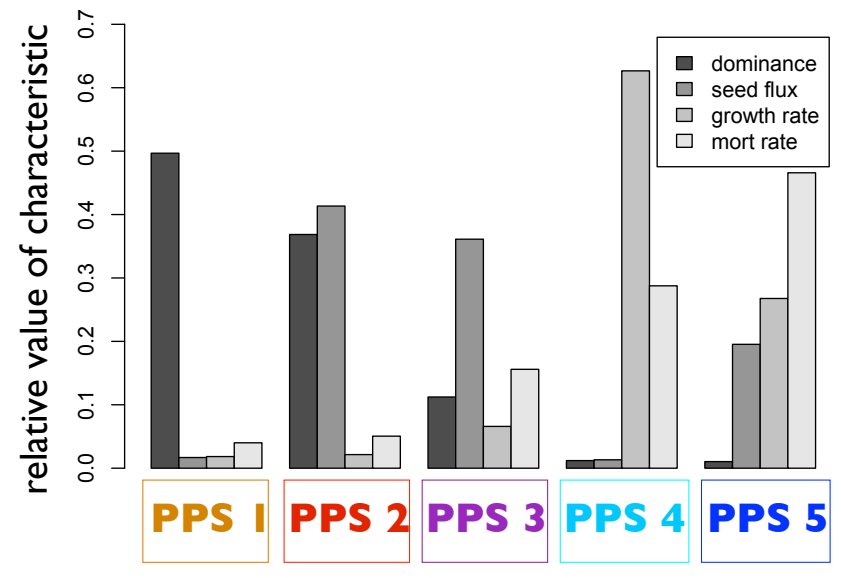

Fig. 5. The five PPSs, each expressed by a different colour with their four characteristics (dominance $d_{i}$, seed flux $f_{\text {seed, } i}$, growth rate $\kappa_{\text {grow, } i}$ and mortality rate $\kappa_{\text {mort }, i}$ ). The colours refer to the same PPSs in the following figures. Characteristic are normalised by their sum, see Table 2 for specific numeric values.

We ran JeDi in order to generate a number of PPSs that are viable under such climatic conditions. 500 PPS were seeded, each grew, reproduced or died in isolation from all others. After $500 \mathrm{yr}$, all PPS were at equilibrium with 386 of the initial populations becoming extinct, having zero biomass and not produced any seeds. From the 114 viable populations, five were chosen that reflected a range of different growing strategies, such as coloniser or competitor.

The characteristics of the five PPSs can be seen in Table 2, and are compared to each other in Fig. 5. They are ordered by dominance from high to low: PPS 1 is the most dominant with very low seed flux, mortality and growth rate. It represents a very big tree with low seed production. PPS 2 is less dominant but has a high seed flux with low growth and mortality rate, e.g. a tree with high seed production. PPS 3 has a low dominance with a high seed flux and low growth rate, e.g. a shrub. PPS 4 has a high growth rate but very small seed flux, e.g. a grass. Note that the ratio between growth and mortality rate is high. PPS 5 has the second highest growth rate and intermediate seed flux. It is not dominant and can be thought of as a high seed producing grass.

\subsection{Setup of DIVE simulations}

We ran the DIVE model with the five selected PPSs and calculated the rate of change of the occupied areas of these PPSs over different intensities of resource competition, seed competition and perturbations.

DIVE simulations started from bare area, i.e. $A_{\text {bare }}(t=$ $0)=1$ and $A_{i}(t=0)=0$. When $A_{i}=0$, the actual seed flux is given by $A_{i} \cdot f_{\text {seed, } i}=0$ and the rates of establishment are zero. Therefore it is necessary to start with an initial actual seed flux for the five selected PPSs. This is implemented in 
the first time step by setting $A_{i} \cdot f_{\text {seed }, i}=f_{\text {seed }, i}$ in Eq. (4). All simulation were run for $10000 \mathrm{yr}$ with a daily time step.

To evaluate the role of resource and seed competition as well as perturbations for steady states and transient states of population dynamics, we conducted a series of sensitivity analysis experiments:

- to assess the impact of perturbations, we used the following values for the perturbation parameter: $c_{\text {Mort }}=(0.001,0.05,0.1,1,10)$ in scenarios with seed and resource competition, $c_{\mathrm{R} 1}=1$ and $c_{\mathrm{R} 2}=1$

- to assess the impacts of seed and resource competition we used combinations of strong $\left(c_{\mathrm{R} 1}=1\right)$ or neutral seed competition $\left(c_{\mathrm{R} 1}=10^{9}\right)$ with strong $\left(c_{\mathrm{R} 2}=1\right)$ or neutral resource competition $\left(c_{\mathrm{R} 1}=10^{9}\right)$ under two perturbation scenarios, $c_{\text {Mort }}=0.05$ and 1 .

- to investigate the effects of competition on diversity, we changed the strength of both types of competition from strong to neutral, $c_{\mathrm{R} 1,2}=\left(1,2,4,8,16,32,10^{9}\right)$. We used three different values for $c_{\text {Mort }}=(0.001,0.05,10)$.

\subsection{Analysis}

To assess the quality of the simulated succession for the sensitivities to perturbation and competition, we plot time-series of the occupied areas $A_{i}$. The effects of perturbations and competition on diversity were evaluated using the Shannon Index of biodiversity. This index is defined by

$H=-\sum_{i=1}^{n}\left(\frac{A_{i}}{\sum_{k=1}^{n} A_{k}} \cdot \log \left(\frac{A_{i}}{\sum_{k=1}^{n} A_{k}}\right)\right)$

This diversity index is minimal with $H=0$ if not more than 1 PPS occupies an area $A_{k}>0$. Diversity is at a maximum with $H=1.61$, if all PPSs occupy equal areas.

\section{Results}

\subsection{The role of perturbations}

Different values of perturbations under high resource and seed competition lead to different successional patterns and to steady states of competitive exclusion, coexistence and total extinction (Fig. 6). The first PPS to increase is the fastgrowing grass-like PPS 5, followed by the shrub-like PPS 3 to slow-growing tree-like PPS 2 and 1. Under conditions of low perturbations and with both seed and resource competition operating, the largest PPS 1 is the last to increase in area, but then competitively excludes all others (Fig. 6a). As the intensity of perturbations increases, the successional order does not change, but the fast reproducing tree-like PPS 2 increases in area and coexists with the most dominant PPS 1 (Fig. 6b-c). For higher levels of perturbations, occupied areas of all PPSs decrease and PPS 1 is not able to exist, but still PPS 2 and 3 coexist (Fig. 6d). Under further increased levels of perturbation, none of the PPS can sustainable exist, all go extinct (Fig. 6e). Hence, under high resource and seed competition, intermediate perturbations are required to obtain coexistence. The successional patterns seem reasonable, because they range from fast-growing PPSs towards slow-growing PPSs similar to observed successions in a wide range of ecosystems (MacArthur and Wilson, 1967; Odum, 1969).

\subsection{The role of competition under different perturbations}

We obtained different successional patterns and steady states when resource and seed competition were strong or neutral (Fig. 7). Under conditions of low to intermediate perturbations, turning off resource competition leads to high importance of seed flux (compare Fig. 7a and b, see Table 3). Initially, only the high seed-producing grass-like PPS 5 is present, because it is able to rapidly colonise all available bare area (Fig. 7b). Later, the tree-like PPSs 2 and shrub-like PPS 3 with a high seed flux increase in area and stably coexist while excluding all other PPSs. This situation is reversed when seed competition is turned off and resource competition is turned on, representing a strong selection for size or dominance (see Table 3): PPS 1 almost covers the complete area in steady state (Fig. 7c). Primary succession also has changed, and the low seed-producing grass-like PPS 4 replaces PPS 5 as the most successful strategy. However, all five PPSs are present in early succession. Turning both forms of competition off leads to the emergence of the grass-like PPS 4 with best growth-mortality relationship (Fig. 7d, Table 3). In steady state all five PPSs coexist.

Increasing perturbations to intermediate and high levels leads to coexistence of at least two PPSs, irrespective of strength of seed and resource competition (Fig. 7e-h). Under such conditions there are two main regimes in which either the PPS with greatest seed flux or the one with best growthmortality relationship will occupy most area (Table 3). Seed competition always leads to PPS 2 with highest seed flux to occupy most area, coexisting with PPS 3 (Fig. 7e and f). PPS 4 will be most successful when seed competition is turned off (Fig. 7g and h). This pattern is independent from resource competition, but as resource competition operates, the most dominant PPS 1 is still the second most successful PPS (Fig. 7h).

Hence, we obtain coexistence of all five PPS when resource and seed competition are neutral. But to reproduce successional dynamics ranging from fast-growing toward slow-growing PPS, resource competition needs to be considered. 

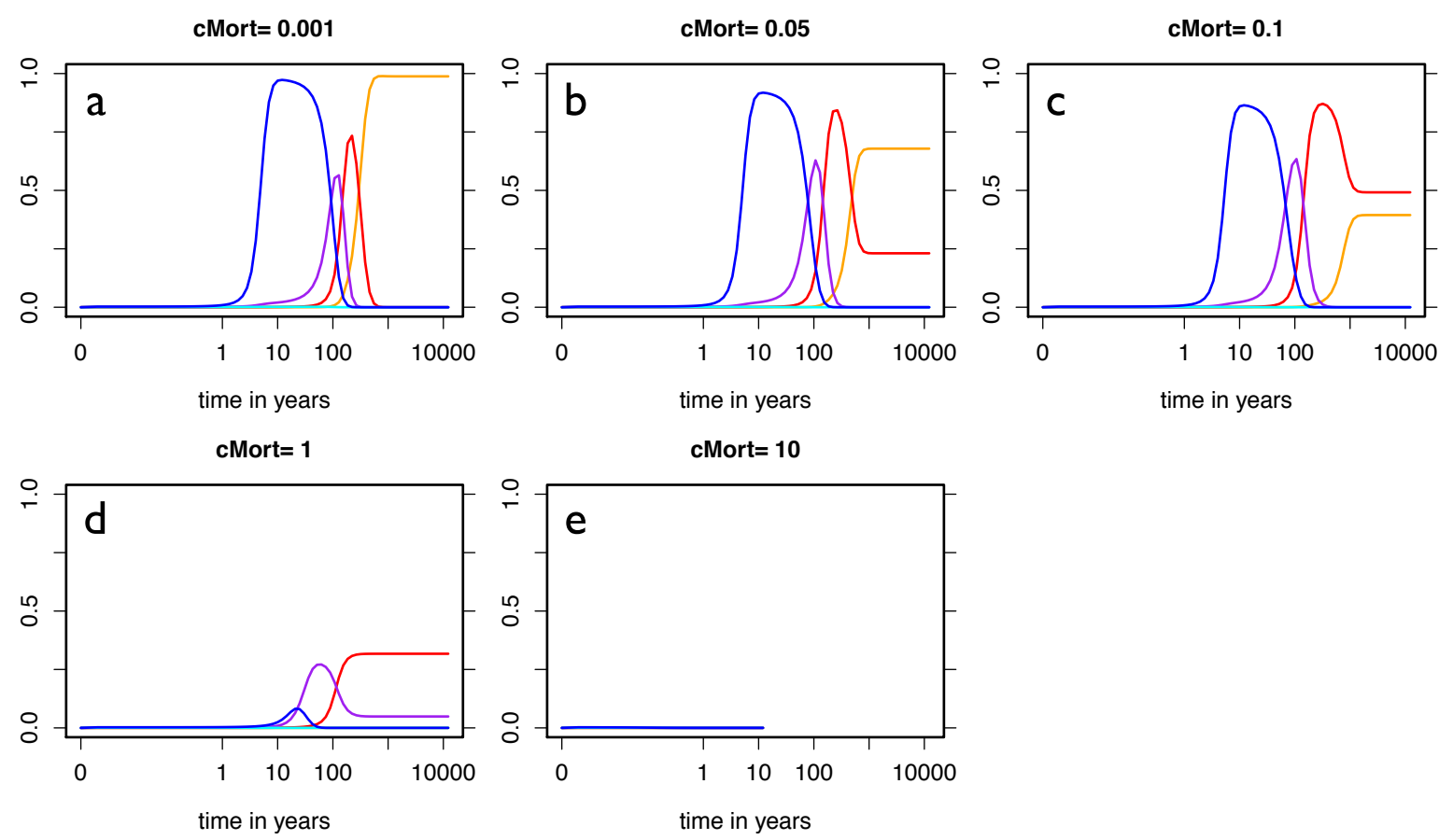

Fig. 6. Time-series of population dynamics under five increasing values for perturbations $\left(c_{\text {Mort }}\right)$ from (a) to (e). The time in years is on logarithmic scale, the y-axis shows the relative abundance or occupied area of each PPS. Colours refer to coloured PPSs in Fig. 5. PPSs interact between seeds and for resources.
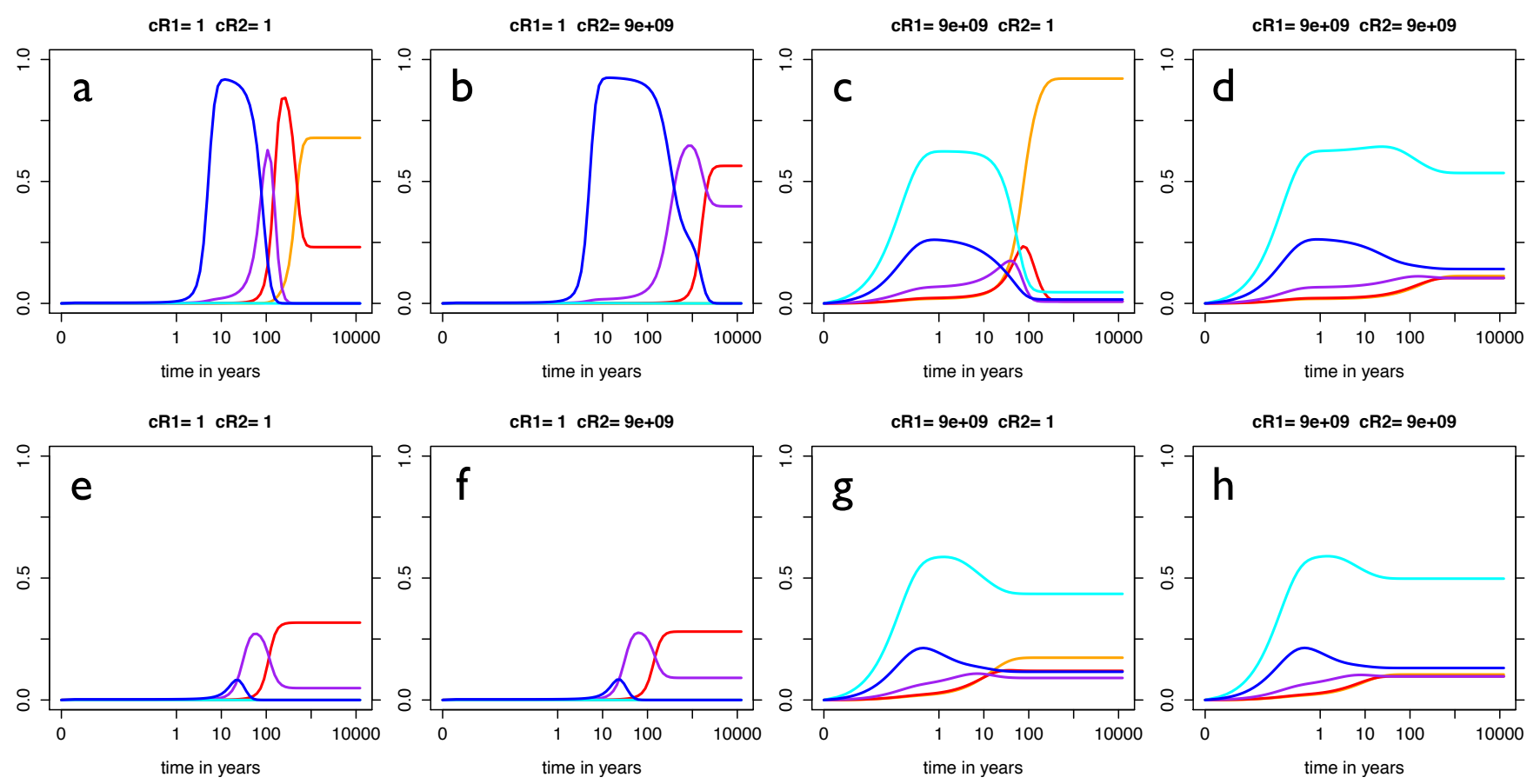

Fig. 7. Time-series of population dynamics for seed competition working $\left(c_{\mathrm{R} 1}=1\right)$ or neutral $\left(c_{\mathrm{R} 1}=9 e+9\right)$, resource competition working $\left(c_{\mathrm{R} 2}=1\right)$ or neutral $\left(c_{\mathrm{R} 2}=9 e+9\right)$ for $c_{\text {Mort }}=0.05(\mathbf{a}-\mathbf{d})$ and $c_{\text {Mort }}=1(\mathbf{e}-\mathbf{h})$. Each colour represents the coverage of a PPS, corresponding to Fig. 5. 
Table 3. Summary of impacts of competition and perturbations for steady state of population dynamics. The most important characteristic to be most abundant in steady state is given and if competitive exclusion (excl) or coexistence (coex) occur. If neither seed or resource competition operate, the ratio $\kappa_{\text {grow }} / \kappa_{\text {mort }}(\mathrm{G} / \mathrm{M})$ is important for being abundant.

\begin{tabular}{|c|c|c|c|c|}
\hline $\begin{array}{l}\text { Seed } \\
\text { comp }\end{array}$ & $\begin{array}{l}\text { Res. } \\
\text { comp }\end{array}$ & $\begin{array}{l}\text { Most } \\
\text { abundant }\end{array}$ & Result & Fig. \\
\hline \multicolumn{5}{|c|}{ Low-intermediate perturbations } \\
\hline on & on & size & excl or coex & $7 \mathrm{a}$ \\
\hline on & off & seed flux & coex & $7 b$ \\
\hline off & on & size & excl or coex & $7 \mathrm{c}$ \\
\hline off & off & $\mathrm{G} / \mathrm{M}$ & coex & $7 d$ \\
\hline \multicolumn{5}{|c|}{ Intermediate-high perturbations } \\
\hline on & on & seed flux & $\operatorname{coex}$ & $7 \mathrm{e}$ \\
\hline on & off & seed flux & coex & $7 f$ \\
\hline off & on & G/M, size & coex & $7 \mathrm{~g}$ \\
\hline off & off & $\mathrm{G} / \mathrm{M}$ & coex & $7 \mathrm{~h}$ \\
\hline
\end{tabular}

\subsection{The role of competition and perturbations for diversity}

Diversity is strongly influenced by perturbations and the strength of competition. Under low perturbations, high strength of both types of competition results in no diversity (Fig. 8a, bottom left). As the values of competition strengths decrease, diversity increases. Under conditions of high resource competition, seed competition plays only a minor role in affecting species diversity at steady state, while under conditions of high seed competition, resource competition can strongly affect diversity (Fig. 8a). Therefore, under low perturbations, resource competition has a strong impact on population composition, while seed competition is less important. For high perturbations, it is the reverse, while resource competition has no effect, seed competition is very important (Fig. 8c). For intermediate perturbations, a shift between both happens (Fig. 8b). Consequently, under increasing perturbations, diversity is decreasingly affected by resources competition while increasingly by seed competition.

\section{Discussion}

We first discuss the limitations of DIVE and then interpret the results in terms of our goal to better understand the interplay and relative importance of perturbations and competition in shaping the diversity of communities. We then discuss possible extensions of the model and potential future applications of DIVE.

\subsection{Limitations}

The limitations we discuss in the following concern the structure of the model in terms of how populations and their dynamics are represented in DIVE as well as the setup of the model. Even though DIVE is designed to represent population dynamics in a very general way and thereby minimize the number of free parameters, it is nevertheless necessary to choose values of the free parameters $c_{\mathrm{R} 1}, c_{\mathrm{R} 2}$, and $c_{\text {Mort }}$ that are associated with competition and mortality.

\subsubsection{Representation of populations}

DIVE models populations dynamics of different PPSs rather than at the level of individual plants, age or height classes. There are models that explicitly represent these population aspects (e.g. Moorcroft et al., 2001; Fisher et al., 2010, represents different height classes). Since mortality may be different at different ages within a population of one PPS, populations may be more adaptive and respond differently to perturbations when different age classes are represented. This effect is not captured by DIVE. A good justification for not including different classes is that this makes the DIVE model much less computationally expensive while potentially allowing for the representation of a greater diversity of PPS in the model.

Populations also do not explicitly compete for resources such as light, water, nutrients etc., and space is considered to be homogeneous. This limitation could be addressed, but it would require a joint representation of the ecophysiological processes of the PPS, which is currently calculated in the JeDi model, and the resulting population dynamics, which is simulated separately by DIVE.

However, despite the simplicity of our approach, we are able to investigate the influence of perturbations, seed and resource competition. As competition might be influenced also by environmental and biological heterogeneity, the inclusion of strength of competition in individual-based spatially explicit models, could lead to even more complex model with more unknown parameters.

\subsubsection{Representation of competition}

DIVE models competition implicitly by assuming that populations with a higher biomass outcompete ones with lower biomass. This assumption is to a first approximation reasonable, since differences in competitive ability result mainly on differences in size. For instance, the acquisition of light depends on size (Bengtsson et al., 1994) such that, for example smaller plants are over-shaded by larger ones (Siemann and Rogers, 2003). But smaller sized plants could also have higher competitive abilities than bigger ones (Keating and Aarssen, 2009). However, to account for different types of resource competition within one model equation, it makes sense to incorporate resource competition and its strength by 


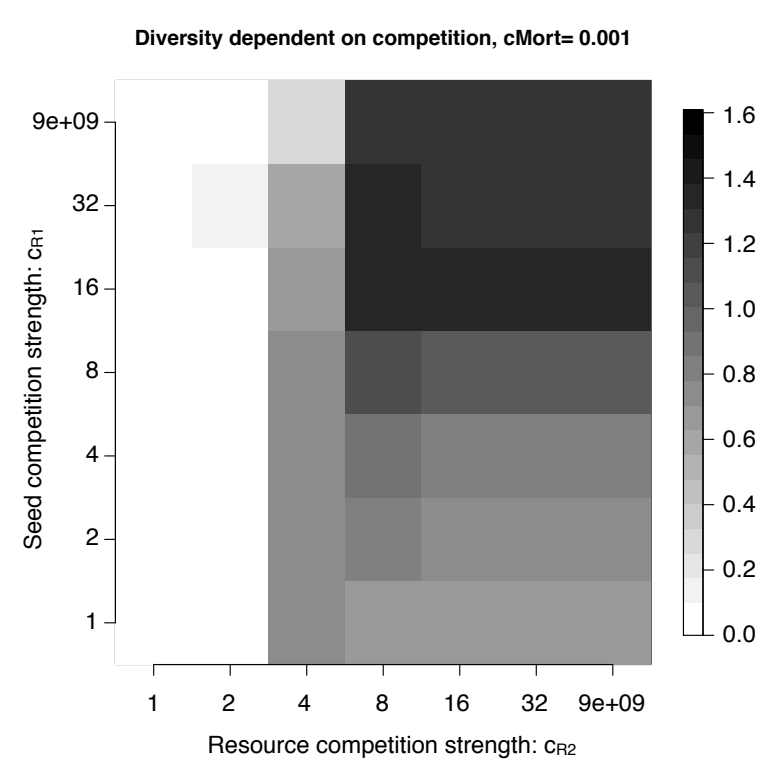

(a) low perturbations

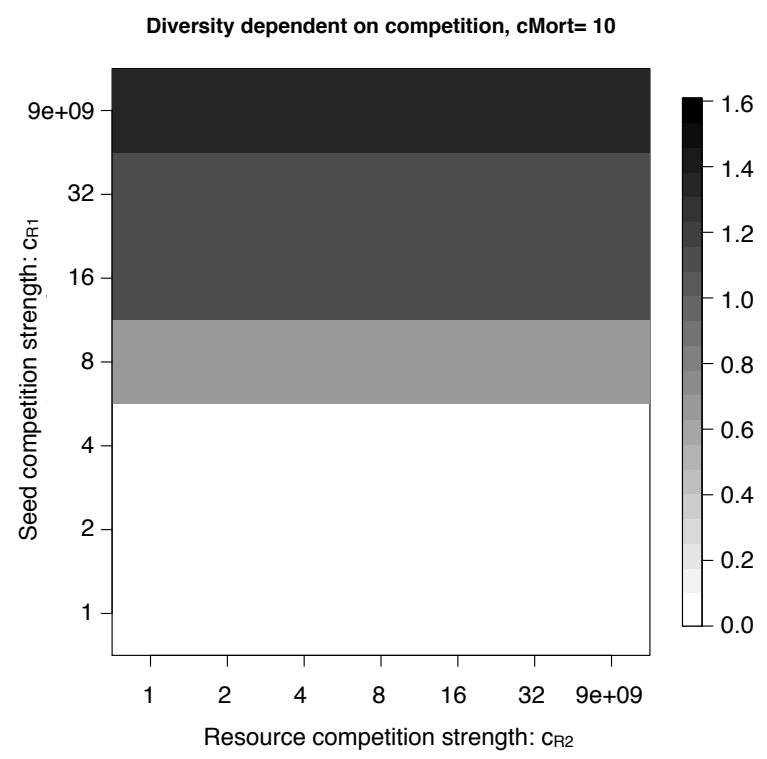

(c) high perturbations

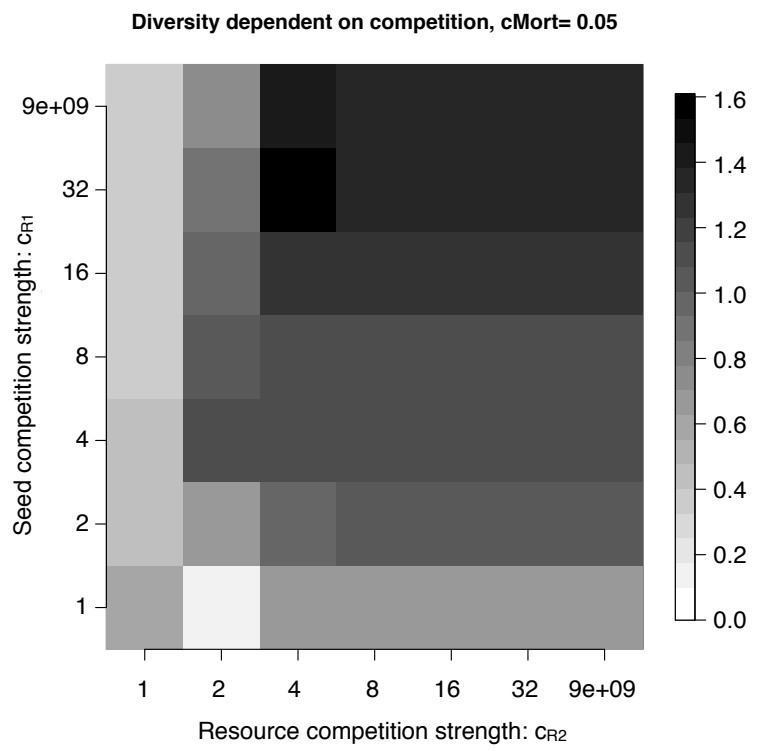

(b) intermediate perturbations

Fig. 8. Each point represents the diversity (Shannon Information Entropy) after $10000 \mathrm{yr}$ of a DIVE simulation dependent on seed (y-axis) and resource competition (x-axis). The values for the strength of seed competition decrease bottom to top and for the strength of resource competition decrease from left to right.

using a simple approach, because larger plants are likely to be better competitors (Keating and Aarssen, 2009). DIVE uses plant strategy parameters that emerge from functional relationships and climatic constraints, such as growth rate and seed production, that then reflect a population's strategy in being a coloniser or competitor. The performance of a PPS directly affects these abilities via e.g. the intrinsic growth rate (Huston, 1979) or seed production (Angert et al., 2009).
In DIVE, only competitive interactions between plants are considered that are detrimental to the abundance of a population. However, interactions can also be positive, resulting in increased performance of neighbouring plants, e.g. a large plant shades a plant adapted to shade (Callaway et al., 2002). With our approach, we do not address such facilitative interactions. This could potentially be implemented in the model if resource competition is represented in a more process-based way, as discussed above. We may, however, 
assume that these are of secondary importance for community dynamics at larger scales.

\subsubsection{Representation of mortality}

We model mortality in a simple way dependent on each PPS characteristics (e.g. biomass) and a PPS-independent perturbation parameter $c_{\text {Mort }}$. While our formulation (see Eq. 6) seems adequate to work for different plant strategies, if we were to use DIVE to analyze specific biomes such as the tropics, in the light of Wright et al. (2010) a better parameterisation could be needed. They concluded e.g. that mortality rates of tropical tree species are in general independent of the maximum height, while wood density was found to be a more important aspect. However, we want to use not only trees but also grasses and shrubs and therefore need a more general parameterisation.

The perturbation parameter $c_{\text {Mort }}$ plays a critical role in affecting the mortality of a PPS. This parameter is introduced to capture the many different types of perturbations in one term, e.g. disease, herbivory, grazing or disturbances such as fire and windfall. We use a constant value for this parameter, even though many disturbances are stochastic and to some extent dependent on the climatic conditions - as is the case for fire - or on the composition of the community - as is the case for herbivory. Stochastic perturbation events have major impacts on vegetation dynamics (Johst and Huth, 2005), and different PPSs may respond differentially to perturbations. Diaz et al. (2007), for instance, concluded that grazing, which expresses a form of perturbation, interacts with species composition. This deficit could be addressed by modeling the value of $c_{\text {Mort }}$ stochastically, and by modeling the associated processes that represent perturbations more explicitly.

While there has been progress in understanding mortality, disturbances and perturbations (e.g. Negrón-Juárez et al., 2010; Lines et al., 2010; Chao et al., 2008), challenges still remain with respect to the quantification of perturbation rates, as these values might differ in specific regions of the Earth. Given these limitations, we chose this parameter to be fixed, because we wanted to include perturbations in a simple and transparent way. A better representation of the different forms of perturbations at the global scale for many different PPSs is a great challenge and it is a parsimonious assumption that, in sum, its effects might be equal to all species.

\subsubsection{Choice of PPS}

The choice of the five PPS was somewhat arbitrary. This was done to be able to clearly analyze the dynamics of DIVE and attribute these to the choice of the three open parameters. In future applications, there is in principle no limit to the number of interacting populations. This is particularly important when we want to use DIVE to better understand diversity patterns in terms of the associated coexistence of PPSs as well as their geographical variation. For this we would need to represent many more PPS in DIVE.

Also, the selected PPS are not based on observed characteristics, so it may seem that the simulated dynamics are somewhat artificial. In principle one could use empirical data of ecological succession to determine realistic parameter values for each ecosystem to tune the dynamics of DIVE. This would then, however, remove the general nature of the DIVE approach. By using the simulated characteristics from the JeDi model, one captures the generality of the range of PPSs that can cope with the climatic conditions within a region. An alternative strategy for improving the representation of plant function might be to concentrate on the depiction of ecophysiological trade-offs within JeDi (or similar models).

\subsubsection{Constant climatic forcing}

We used a hypothetical tropical climatic forcing in the simulations. This was done to avoid the effects of climatic variability on population dynamics so that the simulated population dynamics could be more easily attributed to the choice of parameters $c_{\mathrm{R} 1}, c_{\mathrm{R} 2}$, and $c_{\text {Mort }}$. This tropical forcing provides the conditions under which the greatest diversity of PPS's can survive.

Under different climatic settings, e.g. seasonal or interannually varying climates, the population dynamics would clearly be affected by the seasonality, and the sensitivities to the free parameters would possibly be different to some extent. This potential limitation could easily be addressed in the future by prescribing realistic climatic forcing.

\subsection{Interpretation}

Despite its simplicity and potential limitations, DIVE is able to capture the essential basics of population dynamics. With an adequate choice of the three open parameters $c_{\mathrm{R} 1}, c_{\mathrm{R} 2}$, and $c_{\text {Mort }}$, it is able to represent realistic successional dynamics as well as their sensitivity to the intensity of perturbation.

The successional dynamics in DIVE are consistent with the general observed pattern of succession. Communities in early succession are usually dominated by fast-growing species (colonisers), while in later succession by slowgrowing species (competitor) (Odum, 1969). Fast growing species are represented in DIVE by PPSs that rapidly establish due to a high growth rate and high seed flux (colonisers). Competitors are represented in DIVE by PPSs that are slow growing and gain a high biomass, thereby able to exclude others. In early succession in a DIVE simulation, colonisers are highly abundant, competitors are at low abundance and competition for resources plays a minor role in determining the PPS composition at this stage. As time progresses and bare area becomes limited, establishment decreases and colonisers are replaced by competitors, consistent with the real world (e.g. Huston and Smith, 1987). At this stage, the role of invasion and exclusion, i.e. resource competition, is 
more import than establishment in shaping community composition. As PPSs compete for resources, PPSs with high biomass steadily invade the area occupied by PPS with lower biomass by capturing more of the available space (Tilman, 1990). When small PPSs are not able to compensate exclusion with establishment, they become extinct. Hence, these dynamics in DIVE are fully consistent with observations and established ecological theory.

The sensitivity of the simulated population composition to the strength of perturbations is also consistent with observations. We found that under low perturbations, the composition was determined by late-successional strategies (competitors), while under high perturbations it was determined by early successional strategies (coloniser). These outcomes are consistent with Johst and Huth (2005). Furthermore, the intensity of perturbations affects how effective less dominant, i.e. PPS with small biomass, are at reclaiming area via establishment and so can determine whether steady states of competitive exclusion or coexistence are achieved. We found that under high levels of competition, intermediate levels of perturbations were required to obtain coexistence. This relationship is consistent with the Intermediate Disturbance Hypothesis (e.g. Grime, 1973; Connell and Fox, 1979), which proposes diversity is highest at intermediate intensity of perturbations. In summary, we conclude that the DIVE model adequately represents population dynamics in a simple way.

To get back to our main motivation of understanding the relative importance of competition and perturbations on community structure, we found that diversity is highest without competition as long as mortality was not too high. However, in the absence of competition, we found that a PPS dominated the steady state which had a low dominance, low seed production, but a high growth rate (Fig. $5 \mathrm{~d}$ and h). This outcome of population dynamics seems unrealistic in terms of natural settings, but could represent a human managed crop land. In a crop land the seed input is high and competition is minimized by management. However, in the presence of seed competition, this PPS was absent, and in the presence of only resource competition, it was less dominant in the community. This would suggest that at least resource competition needs to be considered to obtain reasonable community dynamics in DIVE.

In the presence of resource competition, but no seed competition, we found high diversity during succession, but a final state of competitive exclusion by the most dominant PPS with the highest biomass under low perturbations. The absence of seed competition allowed for all PPS to exist at a minimal level so that diversity can result during succession. To obtain higher levels of diversity in the final state, higher levels of perturbations or a lower strength of resource competition are required.

When only seed competition is considered, we found that this also led to unrealistic outcomes. In this case, we found coexistence, but the steady state community was dominated by the PPS with the highest seed production, and not by the
PPS with the highest dominance (Fig. 5b and f). This finding is consistent with Arora and Boer (2006), who found that strong seed competition leads to unrealistic patterns of competitive exclusion within their model that is based on LotkaVolterra equations. We also found that while the relative abundances were affected by the prescribed intensity of mortality $\left(c_{\text {Mort }}\right)$, the relative dominance was not affected. This result suggests that resource competition seems to be more important in shaping realistic community dynamics than seed competition.

When investigating the diversity of the final state (Fig. 6), we found that resource competition played the more important role than seed competition in the case of low perturbations. At the other extreme of high perturbations, the diversity was shaped by the strength of seed competition and the intensity of resource competition had no effect. Intermediate levels of perturbations led to coexistence and high diversity for the widest range of the strengths in resource and seed competition.

Given that succession and coexistence is observed in plant communities, we conclude that at least resource competition and intermediate levels of perturbation are required to simulate the dynamics of diverse populations.

\subsection{Potential extensions and applications of DIVE}

Current models that attempt to simulate vegetation dynamics, including composition or coexistence of different plants types, do not take into account that the strength of competition can be different in different environments, and for different plant types. Hence, current approaches impose assumptions about the strengths of competition and their effect on community structure. We have shown that the strength of competition and perturbation are critical in determining community structure. Therefore including the effects of resource and seed competition in the current generation of dynamics vegetation models could yield different results.

Thus, as a next step, it would seem important to find out the effects of competition and perturbations on the dynamics and diversity of communities across a range of realistic climates. This can easily be done using global climatologies and by including many more of the simulated PPSs from the JeDi model. This would require to couple the DIVE and JeDi models, as the plant properties needed as an input for DIVE would no longer be constant. Such an investigation would allow us to understand how reasonable the assumption of uniform, constant values for the three open parameters of DIVE are.

DIVE could also be improved by a better representation of perturbations, such as fire, herbivory, and windfall. For some forms of perturbations, process-based models exist, e.g. for fire (Thonicke et al., 2001). Also, competition can be represented in more detail, as discussed above.

Such a model would have a great potential use as it would allow us to investigate not just the role of population 
dynamics and functional diversity on the mean climate, but also the transient dynamics under global changes.

\section{Conclusions}

Understanding how diverse vegetation communities may change and interact with environmental change remains a key scientific challenge. Here we present a simple and general model DIVE that provides an adequate way to model plant population dynamics that could be used for global investigations concerning diversity and global change.

A particular strength of DIVE is that it considers seed competition and resource competition as distinct processes. This is important, because each of them influences population dynamics in a different way, and differently under different intensities of perturbations. We found that, diversity is highest under neutral seed and resource competition. However, to obtain reasonable successional dynamics, at least resource competition needs to be considered. Intermediate levels of perturbations are required to achieve coexistence under high strength of competition, which is consistent with the Intermediate Disturbance Hypothesis. In conclusion, at least resource competition and intermediate levels of perturbation are required to simulate realistic dynamics of diverse populations.

A promising next step will be to investigate how the strengths of seed and resource competition affect population dynamics in different climatic settings and what effect this may have for diversity patterns. In the future, an integration of the DIVE into the JeDi model can be used to study how global change affects global vegetation, diversity patterns and surface exchange fluxes of water and carbon in a process-based way.

Acknowledgements. The authors would like to thank the Max Planck society for supporting the Biospheric Theory and Modeling Group. We also want to thank Rosie Fisher and an anonymous the referee for their positive and constructive comments. Finally K. B. want to thank J. Engel, A. Rammig and F. Angermüller for their stimulating discussions on an earlier version of the manuscript.

The service charges for this open access publication have been covered by the Max Planck Society.

Edited by: U. Seibt

\section{References}

Angert, A. L., Huxman, T. E., Chesson, P., and Venable, D. L.: Functional tradeoffs determine species coexistence via the storage effect, P. Natl. Acad. Sci. USA, 106, 11641-11645, 2009.

Arora, V. K. and Boer, G. J.: Simulating competition and coexistence between plant functional types in a dynamic vegetation model, Earth Interact., 10, 1-30, 2006.

Badeck, F., Lischke, H., Bugmann, H., Hickler, T., Honninger, K., Lasch, P., Lexer, M., Mouillot, F., Schaber, J., and Smith, B.:
Tree species composition in European pristine forests: Comparison of stand data to model predictions, Climatic Change, 51, 307-347, 2001.

Bengtsson, J., Fagerstrom, T., and Rydin, H.: Competition and coexistence in plant communitites, Trends Ecol. Evol., 9, 246-250, 1994.

Box, E.: Predicting physiognomic vegetation types with climate variables, Vegetatio, 45, 127-139, 1981.

Brown, J., Gillooly, J., Allen, A., Savage, V., and West, G.: Toward a metabolic theory of ecology, Ecology, 85, 1771-1789, 2004.

Bugmann, H.: A review of forest gap models, Climatic Change, 51, 259-305, 2001.

Bunker, D., DeClerck, F., Bradford, J., Colwell, R., Perfecto, I., Phillips, O., Sankaran, M., and Naeem, S.: Species loss and aboveground carbon storage in a tropical forest, Science, 310, 1029-1031, 2005.

Callaway, R., Brooker, R., Choler, P., Kikvidze, Z., Lortie, C., Michalet, R., Paolini, L., Pugnaire, F., Newingham, B., Aschehoug, E., Armas, C., Kikodze, D., and Cook, B.: Positive interactions among alpine plants increase with stress, Nature, 417 , 844-848, 2002.

Chao, K.-J., Phillips, O. L., Gloor, E., Monteagudo, A., TorresLezama, A., and Martinez, R. V.: Growth and wood density predict tree mortality in Amazon forests, J. Ecol., 96, 281-292, 2008.

Chesson, P. and Huntly, N.: The roles of harsh and fluctuating conditions in the dynamics of ecological communities, Am. Nat., 150, 519-553, 1997.

Clements, F.: Nature and structure of the climax, J. Ecol., 24, 252284, 1936.

Connell, J. and Fox, J.: Intermediate-Disturbance Hypothesis, Science, 204, 1344-1345, 1979.

Cox, P.: Description of the TRIFFID Dynamic Global Vegetation Model, Hadley Centre, Technical note 24, 2001.

Diaz, S., Lavorel, S., McIntyre, S., Falczuk, V., Casanoves, F., Milchunas, D. G., Skarpe, C., Rusch, G., Sternberg, M., NoyMeir, I., Landsberg, J., Zhang, W., Clark, H., and Campbell, B. D.: Plant trait responses to grazing - a global synthesis, Glob. Change Biol., 13, 313-341, 2007.

Fisher, R., McDowell, N., Purves, D., Moorcroft, P., Sitch, S., Cox, P., Huntingford, C., Meir, P., and Woodward, F.: Assessing uncertainties in a second-generation dynamic vegetation model caused by ecological scale limitations, New Phytol., 187, 666681, 2010.

Foley, J., Prentice, I., Ramankutty, N., Levis, S., Pollard, D., Sitch, S., and Haxeltine, A.: An integrated biosphere model of land surface processes, terrestrial carbon balance, and vegetation dynamics, Global Biogeochem. Cy., 10, 603-628, 1996.

Gillooly, J., Brown, J., West, G., Savage, V., and Charnov, E.: Effects of size and temperature on metabolic rate, Science, 293 2248-2251, 2001

Grime, J.: Competitive Exclusion in Herbaceous Vegetation, Nature, 242, 344-347, 1973.

Grime, J.: Evidence for existence of 3 primary strategies in plants and its relevance to ecological and evolutionary theory, Am. Nat. 111, 1169-1194, 1977.

Haxeltine, A. and Prentice, I.: BIOME3: An equilibrium terrestrial biosphere model based on ecophysiological constraints, resource availability, and competition among plant functional 
types, Global Biogeochem. Cy., 10, 693-709, 1996.

Hickler, T., Smith, B., Sykes, M., Davis, M., Sugita, S., and Walker, K.: Using a generalized vegetation model to simulate vegetation dynamics in northeastern USA, Ecology, notes LPJ-GUESS, 85, 519-530, 2004.

Hoegh-Guldberg, O., Hughes, L., McIntyre, S., Lindenmayer, D. B., Parmesan, C., Possingham, H. P., and Thomas, C. D.: Assisted colonization and rapid climate change, Science, 321, 345-346, 2008.

Hughes, L.: Biological consequences of global warming: is the signal already apparent?, Trends Ecol. Evol., 15, 56-61, 2000.

Huston, M.: General Hypothesis of species-diversity, Am. Nat., 113, 81-101, 1979.

Huston, M. and Smith, T.: Plant succession: Life history and competition, Am. Nat., 130, 168-198, 1987.

Johst, K. and Huth, A.: Testing the intermediate disturbance hypothesis: when will there be two peaks of diversity?, Divers. Distrib., 11, 111-120, 2005.

Keating, L. M. and Aarssen, L. W.: Big plants-do they limit species coexistence?, J. Plant. Ecol.-UK, 2, 119-124, 2009.

Kleidon, A. and Mooney, H. A.: A global distribution of biodiversity inferred from climatic constraints: results from a processbased modelling study, Glob. Change Biol., 6, 507-523, 2000.

Kleidon, A., Adams, J., Pavlick, R., and Reu, B.: Simulated geographic variations of plant species richness, evenness and abundance using climatic constraints on plant functional diversity, Environ. Res. Lett., 4, 014007, doi:10.1088/1748-9326/4/1/014007, 2009.

Körner, C.: Tropical forests in a Co-2-rich world, Climatic Change, 39, 297-315, 1998.

Lines, E. R., Coomes, D. A., and Purves, D. W.: Influences of Forest Structure, Climate and Species Composition on Tree Mortality across the Eastern US, Plos One, 5, e13212, doi:10.1371/journal.pone.0013212, 2010.

MacArthur, R. and Wilson, E.: The Theory of Island Biogeography, Princeton University Press, 1967.

McCoy, M. and Gillooly, J.: Predicting natural mortality rates of plants and animals, Ecol. Lett., 11, 710-716, 2008.

Moorcroft, P., Hurtt, G., and Pacala, S.: A method for scaling vegetation dynamics: The ecosystem demography model (ED), Ecol. Monogr., 71, 557-585, 2001.

Negrón-Juárez, R., Chambers, J., Guimaraes, G., Zeng, H., Raupp, C., Marra, D., Ribeiro, G., Saatchi, S., Nelson, B., and Higuchi, N.: Widespread Amazon forest tree mortality from a single cross-basin squall line event, Geophys. Res. Lett., 37, L16701, doi:10.1029/2010GL043733, 2010.

Odum, E.: The strategy of ecosystem development, Science, 164, 262-70, 1969.

Parmesan, C. and Yohe, G.: A globally coherent fingerprint of climate change impacts across natural systems, Nature, 421, 37-42, 2003.

Raizada, P., Singh, A., and Raghubanshi, A. S.: Comparative response of seedlings of selected native dry tropical and alien invasive species to $\mathrm{CO}_{2}$ enrichment, J. Plant. Ecol.-UK, 2, 69-75, 2009

Reu, B., Proulx, R., Bohn, K., Dyke, J. G., Kleidon, A., Pavlick, R., and Schmidtlein, S.: The role of climate and plant functional trade-offs in shaping global biome and biodiversity patterns, Global Ecol. Biogeogr., doi:10.1111/j.1466-8238.2010.00621.x, in press, 2011.

Ricklefs, R. E.: Evolutionary theories of aging: Confirmation of a fundamental prediction, with implications for the genetic basis and evolution of life span, Am. Nat., 152, 24-44, 1998.

Sandel, B., Goldstein, L. J., Kraft, N. J., Okie, J. G., Shuldman, M. I., Ackerly, D. D., Cleland, E. E., and Suding, K. N.: Contrasting trait responses in plant communities to experimental and geographic variation in precipitation, New Phytol., 188, 565575, 2010.

Sato, H., Itoh, A., and Kohyama, T.: SEIB-DGVM: A new dynamic global vegetation model using a spatially explicit individualbased approach, Ecol. Model., 200, 279-307, 2007.

Shaver, G., Canadell, J., Chapin, F., Gurevitch, J., Harte, J., Henry, G., Ineson, P., Jonasson, S., Melillo, J., Pitelka, L., and Rustad, L.: Global warming and terrestrial ecosystems: A conceptual framework for analysis, Bioscience, 50, 871-882, 2000.

Siemann, E. and Rogers, W.: Changes in light and nitrogen availability under pioneer trees may indirectly facilitate tree invasions of grasslands, J. Ecol., 91, 923-931, 2003.

Sitch, S., Smith, B., Prentice, I., Arneth, A., Bondeau, A., Cramer, W., Kaplan, J., Levis, S., Lucht, W., Sykes, M., Thonicke, K., and Venevsky, S.: Evaluation of ecosystem dynamics, plant geography and terrestrial carbon cycling in the LPJ dynamic global vegetation model, Glob. Change Biol., 9, 161-185, 2003.

Sitch, S., Huntingford, C., Gedney, N., Levy, P. E., Lomas, M., Piao, S. L., Betts, R., Ciais, P., Cox, P., Friedlingstein, P., Jones, C. D., Prentice, I. C., and Woodward, F. I.: Evaluation of the terrestrial carbon cycle, future plant geography and climate-carbon cycle feedbacks using five Dynamic Global Vegetation Models (DGVMs), Glob. Change Biol., 14, 2015-2039, 2008.

Sousa, W.: The Role of Disturbance in Natural Communities, Annu. Rev. Ecol. Syst., 15, 353-391, 1984.

Thonicke, K., Venevsky, S., Sitch, S., and Cramer, W.: The role of fire disturbance for global vegetation dynamics: coupling fire into a Dynamic Global Vegetation Model, Global Ecol. Biogeogr., 10, 661-677, 2001.

Tilman, D.: Constraints and tradeoffs - towards a predicitve theory of competition and succession, Oikos, 58, 3-15, 1990.

Tilman, D.: Competition and biodiversity in spatially structures habitats, Ecology, 75, 2-16, 1994.

Tilman, D. and Kareiva, P.: Spatial ecology. The role of space in population dynamics and interspecific interactions, Monographs in population biology, 30, 185-250, 1997.

Woodward, F.: Climate and Plant Distribution, Cambridge University Press, Cambridge, 1987.

Woodward, F. and Lomas, M.: Vegetation dynamics - simulating responses to climatic change, Biol. Rev., 79, 643-670, 2004.

Wright, S. J., Kitajima, K., Kraft, N. J. B., Reich, P. B., Wright, I. J., Bunker, D. E., Condit, R., Dalling, J. W., Davies, S. J., Díaz, S., Engelbrecht, B. M. J., Harms, K. E., Hubbell, S. P., Marks, C. O., Ruiz-Jaen, M. C., Salvador, C. M., and Zanne, A. E.: Functional traits and the growth-mortality trade-off in tropical trees, Ecology, 91, 3664-3674, 2010.

Zavaleta, E., Shaw, M., Chiariello, N., Mooney, H., and Field, C.: Additive effects of simulated climate changes, elevated $\mathrm{CO}_{2}$, and nitrogen deposition on grassland diversity, P. Natl. Acad. Sci. USA, 100, 7650-7654, 2003. 